\title{
sciendo
}

\section{Bertrand competition under asymmetric conditions}

\author{
Alexandra VINTILA \\ Bucharest University of Economic Studies, Bucharest, Romania \\ vintilaalexandra14@stud.ase.ro \\ Mihai Daniel ROMAN \\ Bucharest University of Economic Studies, Bucharest, Romania \\ mihai.roman@ase.ro
}

\begin{abstract}
Analyzing price competition through game theory is one of the most important frameworks of oligopoly theory, especially in industrial organizations. Numerous studies have been conducted in this direction, as companies are forced to adjust their sustainable pricing policy to operate in the long term. Thus, the players make a regular adjustment of the pricing strategy. Of all the models developed based on Bertrand's reference model (1883), the most analyzed were those in which informational symmetry predominated. Since informational symmetry presents only a theoretical framework, economists have turned their attention to information asymmetry. This type of information best describes a complex economic game, as it creates an information gap between players and generates opportunities in the decision-making process. Thus, asymmetric information is the main parameter of the decision-making process that determines decision makers to resort to different decision strategies than those assumed by the analytical model. Any asymmetric Bertrand model predicts competitive and efficient market outcomes, a direct relationship between a firm's conduct, market structure and finally market performance. This paper undertakes an analysis of the Bertrand model in the case of demand and asymmetric costs. We determine the Bertrand-Nash equilibrium under the scenario in which close, but not perfect substitutes exist for the differentiated product with hypothetical data. Then we highlight what happens with profits when we consider that discrete cross marginal demand gradually increases. For more research, there are numerous studies based on sequential games, Bayesian games and signaling games both in discrete time and in continuous time.
\end{abstract}

Keywords: Bertrand Model, game theory, asymmetric information, price strategy, Nash Equilibrium

\section{Introduction}

Modeling the behavior of microeconomic entities in conditions of asymmetric information is one of the most complex and interesting areas of analysis. The studies are based on both behavioral analysis of economic agents and analysis of competition. The dynamic structure of the economic game determines companies to adopt either an actual or a future market behavior, through which to ensure their continuity, to attract the appropriate market segments and development strategies and to obtain competitive advantage. Outlining the strategic landmarks, the business model is most often made in the absence of indispensable information to these informed choices. The positioning of a microeconomic entity on the market denotes the multitude of strategies available that allow the attraction of a large segment of customers, thus implying an increase in market power.

The analysis of the behavior of microeconomic entities is based on the opponents' response to the decisions given by the price evolution. In order to gain a competitive advantage, which denotes the success or failure of a microeconomic entity, and to continue its long-term activity in a market, an economic player must adopt a sustainable pricing policy. Thus, the rationale behind price decisions creates both constraints and opportunities. 
Microeconomic entities seek to gather data, find out additional information that they analyze, then establish a probability of making a profit and make an optimal decision to behave in risky conditions. By adopting such approaches, any economic game becomes the result of a rational behavior, based on mathematical modeling. For this reason, decisions based on the tools offered by game theory are taken in the process of procurement, pricing, defining the investment portfolio or making business connections with various partners. Studies conducted in this field demonstrate how game theory can be used in business and also the importance of this decisionmaking tool in economic results. Achstatter (1996) stated that the implementation of strategic decision-making tools offered by game theory in a competitive environment differentiates between failure and success.

Game theory allows modeling and analysis of companies' behavior in situations of information asymmetry because agents do not know exactly the preferences, strategies and constraints of opponents. Modeling economic transactions through game theory reveals a strategic decision-making process. This involves the analysis of strategic interactions, focusing on both actions and decisions of microeconomic entities. Following the analysis of studies focused on the development of this branch of microeconomics, we can see both how the outcome of complex decision-making processes is predicted, and how the player can improve his decision-making skills and even negotiation skills.

This paper is structured as follows. First of all, we review the literature regarding the Bertrand competition and make a brief discussion of relevant theoretical contributions from game theory and asymmetric information respectively to present the framework for the research objectives of interest. The next section describes the methodology and the variable used in the Bertrand model, followed by a simulation and a discussion of results and implications. The paper ends with a section of conclusions, establishing directions for future research.

\section{Literature review}

The strategic interaction between price-related microeconomic entities was analyzed through the Bertrand (1883) model, which has a significant impact on the Nash equilibrium. In this case, firms select the prices for their products and then the corresponding function of the market demand determines the production quantities for each firm. Thus, microeconomic entities must take into account the strategic behavior of rival players that reveal information through price signals. Numerous analyzes were required to outline the well-defined solution of the Bertrand model with asymmetric costs. The existence of a discrete price space is among the hypotheses of the analysis performed (Tirole, 1988).

According to Singh and Vives (1984), Bertrand competition is more efficient than Cournot competition, because, at equilibrium, both consumer surplus and total surplus are higher regardless of the nature of the goods that can be complementary or substitutable, but also the degree of symmetry in a linear structure of demand.

Deneckere and Davidson (1985) studied mergers when firms produce differentiated goods and engage in a Bertrand-type competition. Through empirical analysis, the authors have shown that mergers are beneficial regardless of their size, generating greater economic performance for players. Higgins et al. (2004) stated that horizontal mergers do not have a significant impact on price, quantity offered, consumer surplus and total in the case of Bertrand competition.

Dastidar (1995) considered a classic Bertrand price game in which economic agents commit to respond to the entire market demand, having strictly related cost functions. In such a game, there is a continuum of pure Bertrand equilibrium strategy in which players only gain. In the presence 
of asymmetric information, market power is directly proportional to a competitive pricing policy. Thus, the competitive equilibrium always belongs to the Bertrand equilibrium state. The result obtained after Dastidar's analysis is also valid if the players adopt mixed strategies. In order to analyze price competition, Spulber (1995) outlined a framework for examining the effects of unknown costs on rival players in the Bertrand model. The discontinuity in the Bertrand model is eliminated by the presence of asymmetric information, significantly modifying the properties of the market equilibrium. In the Bertrand-Nash equilibrium, firms have higher prices than marginal costs and a positive expected financial result in the face of unknown costs of rival players. Therefore, both equilibrium price and expected profit depend on the market structure, often producing incentives to enter the market.

Starting from the general hypothesis that a Bertrand type competition is generally considered more efficient in terms of well-being than the Cournot type competition, Lofaro (2002) pointed out that in the presence of incomplete information about opponents' costs, this is not always true. In the presence of uniformly distributed costs, the Bertrand price (production) is different from the Cournot price. In addition, the expected profits of each player, as well as the actual profits are often higher in the Bertrand game. Therefore, even when the Bertrand price is higher than the Cournot price, the Bertrand model can still lead to a higher level of social welfare than the Cournot model because it is more productive.

Economic and business conditions, consumer preferences, and competitive challenges are dynamic, increasing the uncertainty on the market. Thus, information becomes a critical resource in the decision-making process. Day (1990), Glazer (1991), Sarvary and Parker (1997) proposed conceptual frameworks to emphasize the impact of private information, including that coming from competing sources, on the performance of microeconomic entities. Drawing on these conceptual frameworks, Raju and Roy (2000) developed a theoretical model to understand how the characteristics of firms and the industries in which they operate moderate the impact of private information on economic performance. The authors stressed that private information is more valuable when the degree of substitution between goods is higher. This confirms the importance of having private information in more competitive industries. More accurate private information has a significant impact on profits in the case of Stackelberg than in the case of Bertrand-Nash. Although the value of the information is not affected by the size of the market, it is more valuable to the main players on the market.

Assuming asymmetric entry costs and Bertrand-type competition, Thomas (2002) outlined two previously studied models of two-stage market entry and pricing. Thomas found out that the results depended on the assumption of symmetry. If the players' entry decisions are respected before the pricing is established, the total well-being can increase following the entry of a potential participant on the market. Otherwise, the expected price does not change or decrease after the introduction of a potential participant. Both pricing models aim at increasing the level of competition following the introduction of potential opponents with sufficiently low entry costs.

Blume (2003) pointed out the existence of a Nash equilibrium in mixed strategies in which the more efficient firm sets the price equal to the marginal cost of the opposing player, thus honoring the entire market demand with probability 1.

Hsu and Wang (2005) found that both consumer surplus and total surplus are higher under Bertrand-type competition than under Cournot-type competition, regardless of the nature of the goods.

Routledge (2010) analyzed the classic model of Bertrand-type competition in a market with homogeneous goods, constant marginal costs, but in the presence of uncertainty over the costs of 
opponents. Assuming a symmetrical distribution of market power, Routledge emphasized the existence of a Nash equilibrium in mixed strategies.

Suleymanova and Wey (2011) highlighted Bertrand-type competition in markets with network effects and switching costs. In this analysis, four different market patterns were evoked: monopolization and market sharing, which can be both monotonous and alternative depending on the relationship between switching costs and network effects. Relating to welfare, they identified a fundamental conflict between maximizing consumer surplus and social welfare under the assumption of significant network effects. The impact of switching costs, market expansion and asymmetric costs are variables considered when analyzing economic results. Using a dynamic Bertrand model, they showed the connection between competition and agent discount factors.

Dugar and Mitra (2011) analyzed the Bertrand model on a homogeneous goods market with constant and asymmetric unit costs. In the presence of a significant impact of information asymmetry, more efficient firms set the price at a level higher than the marginal cost of the competitor, while Boone et al. (2012) pointed out through an experimental analysis that a more efficient player will set the price at a level equal to the marginal cost of a less efficient opponent.

Based on the analysis of Aumann (1987), Aoyagi (2018) highlighted the behavior of players in a Bertrand type competition to attract buyers distributed in a network. The value of the good depends on the number of opponents in this network. The author identified a pricing set that is consistent with an equilibrium in which one of the players monopolizes the market. This set of strategies includes both marginal cost prices and bipartisan prices, which offer price reductions to some buyers and charge increases to others.

Kaimann and Hoyer (2019) analyzed price competition (Bertrand) between telecommunications companies and empirically modeled pricing behavior in an oligopoly using the prices of mobile contracts offered by players in the reference period 2011-2017. They highlighted price differences as well as reputational effects which are a signal to buyers and significantly affect market demand. Given that brands can increase demand, the authors point out that they can have side effects even after the price increase.

Rusescu and Roman (2020) also analyzed the case of differentiated products competition using Cournot, Bertrand and Stackelberg models. They determine the quantities, the prices and the profits level in the case of symmetric competition, comparing the efficiency levels for involved competitors.

\section{Methodology}

Any economic game becomes the result of a rational behavior, based on mathematical modeling. Game theory provides models that allow the description of complex strategic situations in an extremely simplified way. This relatively new field of research has been described as an "optimal decision making in the presence of others with different objectives" (Hart, 2005). In the economic literature, the behavior of firms in the case of the Cournot and Bertrand models of duopolistic competition is analyzed through game theory, both statically and dynamically.

In this paper, we analyze a game in which each player sets his price, allowing consumers to choose from where they buy, having as reference the linear duopoly model presented by Singh and Vives (1984). The Bertrand game is also known in economic literature as a game with strategic complements, because the best response of one firm arises in the choice of the other. Also, price competition is highlighted through this model.

We consider two companies that operate on the same market and make strategic choices simultaneously. These have as an optimal criterion the maximization of profit. In the cases of 
Bertrand duopolies, both firms select prices as decision variables, having the following market demand functions:

$\left\{q_{1}=x_{1}-y_{1} p_{1}+z_{1} p_{2} q_{2}=x_{2}-y_{2} p_{2}+z_{2} p_{1}\right.$

where:

- $x=x_{1}+x_{2}$ is the maximum quantity requested on the market;

- $y_{i}$ represents the marginal demand of the good $i$ in relation to its price, if $y_{i}>0$, then we have normal goods;

- $z_{i}$ represents the cross-marginal demand in relation to the other company's price, $p_{j}$;

- if $z_{i}$ is greater than 0 , then substitute goods exist, and if $z_{i}$ is lower than 0 , then complementary goods exist.

So, we assume that the market splits unequally between these firms (asymmetric demand, $\left.x_{1} \neq x_{2}\right)$.

$\mathrm{A}=\left\{p \in R_{2}^{+}: x_{1}-y_{1} p_{1}+z_{1} p_{2}>0, x_{2}-y_{2} p_{2}+z_{2} p_{1}>0\right\}$

Let $C_{1}\left(q_{1}\right)$ and $C_{2}\left(q_{2}\right)$ denote the linear cost functions with asymmetric constant marginal costs without fixed costs:

$\left\{C_{1}\left(q_{1}\right)=c_{1} * q_{1}, c_{1}>0 \quad C_{2}\left(q_{2}\right)=c_{2} * q_{2}, c_{2}>0\right.$

Thus, one of the two players has a cost advantage, expecting most buyers to choose the firm whose price is the lowest.

We determine the Nash equilibrium, the strategy to ensure maximum gains for each player: $p_{i}^{*}=\pi_{i}\left(p_{i}, p_{j}^{*}\right), i, j=\underline{1,2}$

Out of conditions of rationality, the maximum price is higher than constant marginal costs. Thus, the condition of the existence of equilibrium is $S_{i} \in\left[c_{i}, \infty\right)$.

In the case of unique Bertrand-Nash equilibrium, prices are equal to marginal costs, involving such a competitive outcome. Starting from the hypotheses previously mentioned in the case of the Bertrand type equilibrium, we solve the problems of profit maximization for the two companies considered:

$\pi_{1}\left(p_{1}, p_{2}\right)=V_{1}-C_{1}=p_{1} * q_{1}-c_{1} * q_{1}=\left(p_{1}-c_{1}\right)\left(x_{1}-y_{1} p_{1}+z_{1} p_{2}\right)$

$\pi_{1}\left(p_{1}, p_{2}\right)=V_{2}-C_{2}=p_{2} * q_{2}-c_{2} * q_{2}=\left(p_{2}-c_{2}\right)\left(x_{2}-y_{2} p_{2}+z_{2} p_{1}\right)$

To highlight the equilibrium in this case, we start from the two reaction curves determined from first-order condition (also known as marginal revenue).

$F_{1}: \frac{\partial \pi_{1}\left(p_{1}, p_{2}\right)}{\partial p_{1}}=0=>p_{1}=\frac{x_{1}+z_{1} p_{2}+c_{1} y_{1}}{2 y_{1}}$ reaction function of firm $F_{1}$

$p_{1}=f_{1}\left(p_{2}\right)$ reaction curve of firm $F_{1}$ depending on $p_{2}$

Similarly, reaction function and reaction curve of firm $F_{2}$ are determined.

$F_{2}: \frac{\partial \pi_{2}}{\partial p_{2}}=0=>p_{2}=\frac{x_{2}+z_{2} p_{1}+y_{2} c_{2}}{2 y_{2}}$ reaction function of firm $F_{2}$

$p_{2}=f_{2}\left(p_{1}\right)$ reaction curve of firm $F_{2}$ depending on $p_{1}$.

Now, we have to see if the optimal problem at the level of each company admits the maximum.

$\frac{\partial^{2} \pi_{1}\left(p_{1}, p_{2}\right)}{\partial p_{1}^{2}}=-2 y_{1}<0$
$\frac{\partial^{2} \pi_{2}\left(p_{1}, p_{2}\right)}{\partial p_{2}^{2}}=-2 y_{2}<0$

DOI: 10.2478/picbe-2021-0023, pp. 235-244, ISSN 2558-9652 |

Proceedings of the $15^{\text {th }}$ International Conference on Business Excellence 2021 
It is observed that the second order conditions are met in the case of both functions to be optimized.

Under the assumption that companies simultaneously set prices, the equilibrium of the game is obtained as the solution of the system formed by the reaction functions.

$$
\left\{\begin{array}{l}
p_{1}=\frac{x_{1}+z_{1} p_{2}+c_{1} y_{1}}{2 y_{1}}=\frac{z_{1}}{2 y_{1}} p_{2}+\frac{x_{1}+c_{1} y_{1}}{2 y_{1}} \\
p_{2}=\frac{x_{2}+z_{2} p_{1}+y_{2} c_{2}}{2 y_{2}}=\frac{z_{2}}{2 y_{2}} p_{1}+\frac{x_{2}+y_{2} c_{2}}{2 y_{2}}
\end{array}\right.
$$

It is also necessary that the following conditions are met:

$\left\{\frac{z_{1}}{2 y_{1}} \geq c_{1} \frac{z_{2}}{2 y_{2}} \geq c_{2}\right.$

For the considered case, $p_{1}^{*}$ and $p_{2}^{*}$ constitute the equilibrium prices in the conditions of the Bertrand type behavior.

$$
\begin{aligned}
& \left\{p_{1}^{*}=\frac{2 x_{1} y_{2}+2 c_{1} y_{1} y_{2}+x_{2} z_{1}+c_{2} y_{2} z_{1}}{4 y_{1} y_{2}-z_{1} z_{2}}=\frac{z_{1}\left(x_{2}+c_{2} y_{2}\right)+y_{2}\left(2 x_{1}+2 c_{1} y_{1}\right)}{4 y_{1} y_{2}-z_{1} z_{2}} p_{2}^{*}=\frac{x_{1} z_{2}+c_{1} y_{1} z_{2}+2 x_{2} y_{1}+2 c_{2} y_{2} y_{1}}{4 y_{1} y_{2}-z_{1} z_{2}}=\right. \\
& \frac{z_{2}\left(x_{1}+c_{1} y_{1}\right)+y_{1}\left(2 x_{2}+2 c_{2} y_{2}\right)}{4 y_{1} y_{2}-z_{1} z_{2}}
\end{aligned}
$$

If $4 y_{1} y_{2} \neq z_{1} z_{2}$ and $4 y_{1} y_{2}>z_{1} z_{2}$

The profit of the Bertrand firms is given as:

$\left\{\pi_{1}^{*}=q_{1}^{*}\left(p_{1}^{*}-c_{1}\right) \pi_{2}^{*}=q_{2}^{*}\left(p_{2}^{*}-c_{2}\right)\right.$

Therefore, the profit functions of the two firms become:

$$
\begin{aligned}
& \left\{\pi_{1}^{*}=\frac{\left(2 x_{1} y_{1} y_{2}+x_{2} y_{1} z_{1}+c_{2} y_{1} y_{2} z_{1}-2 c_{1} y_{1}^{2} y_{2}+c_{1} y_{1} z_{1} z_{2}\right)\left(x_{2} z_{1}+c_{2} y_{2} z_{1}+2 x_{1} y_{2}-2 c_{1} y_{1} y_{2}+c_{1} z_{1} z_{2}\right)}{\left(4 y_{1} y_{2}-z_{1} z_{2}\right)^{2}} \pi_{2}^{*}=\right. \\
& \frac{\left(2 x_{2} y_{1} y_{2}+x_{1} y_{2} z_{2}+c_{1} y_{1} y_{2} z_{2}+c_{2} y_{2} z_{1} z_{2}-2 c_{2} y_{1} y_{2}^{2}\right)\left(x_{1} z_{2}+c_{1} y_{1} z_{2}+2 x_{2} y_{1}-2 c_{2} y_{1} y_{2}+c_{2} z_{1} z_{2}\right)}{\left(4 y_{1} y_{2}-z_{1} z_{2}\right)^{2}}
\end{aligned}
$$

In order for the two companies to continue to carry out their activity, it is necessary that $\pi_{1}^{*}>0$, respectively $\pi_{2}^{*}>0$, which is reduced to:

$$
\begin{aligned}
& \left\{2 x_{1} y_{1} y_{2}+x_{2} y_{1} z_{1}+c_{2} y_{1} y_{2} z_{1}-2 c_{1} y_{1}^{2} y_{2}+c_{1} y_{1} z_{1} z_{2}>0 x_{2} z_{1}+c_{2} y_{2} z_{1}+2 x_{1} y_{2}-\right. \\
& 2 c_{1} y_{1} y_{2}+c_{1} z_{1} z_{2}>02 x_{2} y_{1} y_{2}+x_{1} y_{2} z_{2}+c_{1} y_{1} y_{2} z_{2}+c_{2} y_{2} z_{1} z_{2}-2 c_{2} y_{1} y_{2}^{2}>0 x_{1} z_{2}+ \\
& c_{1} y_{1} z_{2}+2 x_{2} y_{1}-2 c_{2} y_{1} y_{2}+c_{2} z_{1} z_{2}>0
\end{aligned}
$$

The Nash equilibrium of the game in the general case is represented in Figure 1.

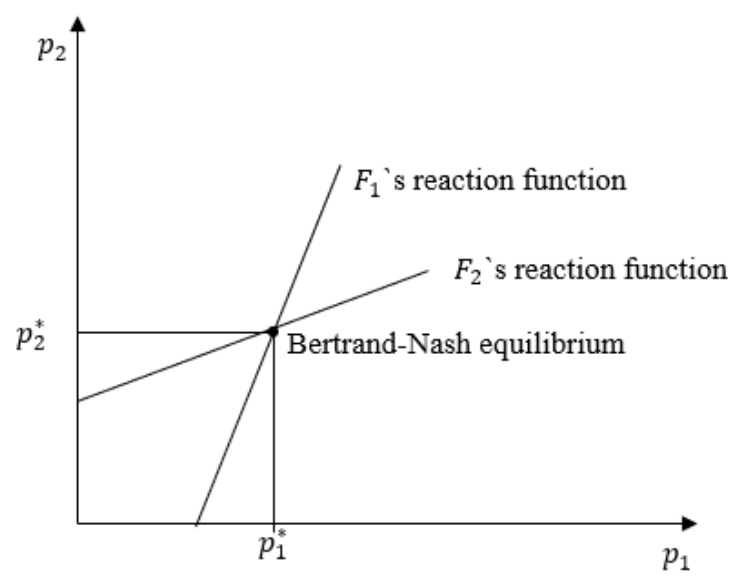

Figure 1. Bertrand duopoly game: best-response functions and Nash equilibrium

Source: own processing. 


\section{Results and discussions}

Having the complete model description, we highlight a variation of the Bertrand game. We consider the scenario in which close, but not perfect substitutes exist for the differentiated product. Consumers find it difficult to substitute differentiated products when there is a high degree of differentiation among products regardless of the type of industry. One of the best-known scenarios of this kind is the mobile phone market. For example, Samsung, an important player in the telecommunication industry, offers differentiated products, but close substitutes are available on the market from competitors.

First of all, we determine the Nash equilibrium in case of a demand and asymmetric costs. Assume $C_{i}\left(q_{i}\right)=c_{i} * q_{i}$ that represents the cost of each firm as before. Now, let $c_{1}=\$ 9$ and $c_{2}=$ $\$ 7$ so that the two firms are not identical. So, $F_{2}$ has a cost advantage. Let the market demand functions still be:

$\left\{q_{1}=100-4 p_{1}+1.9 p_{2} q_{2}=124-4 p_{2}+1.5 p_{1}\right.$

Based on the relationships described in the methodology section, we obtain the following reaction functions:

$\left\{p_{1}=\frac{x_{1}+z_{1} p_{2}+c_{1} y_{1}}{2 y_{1}}=17+0.25 p_{2} p_{2}=\frac{x_{2}+z_{2} p_{1}+y_{2} c_{2}}{2 y_{2}}=19+0.19 p_{1}\right.$

prices:

Plugging $F_{2}$ 's reaction function into $F_{1}$ 's reaction function, we obtain the equilibrium

$\left\{p_{1}^{*}=\$ 22.52 p_{2}^{*}=\$ 23.22\right.$

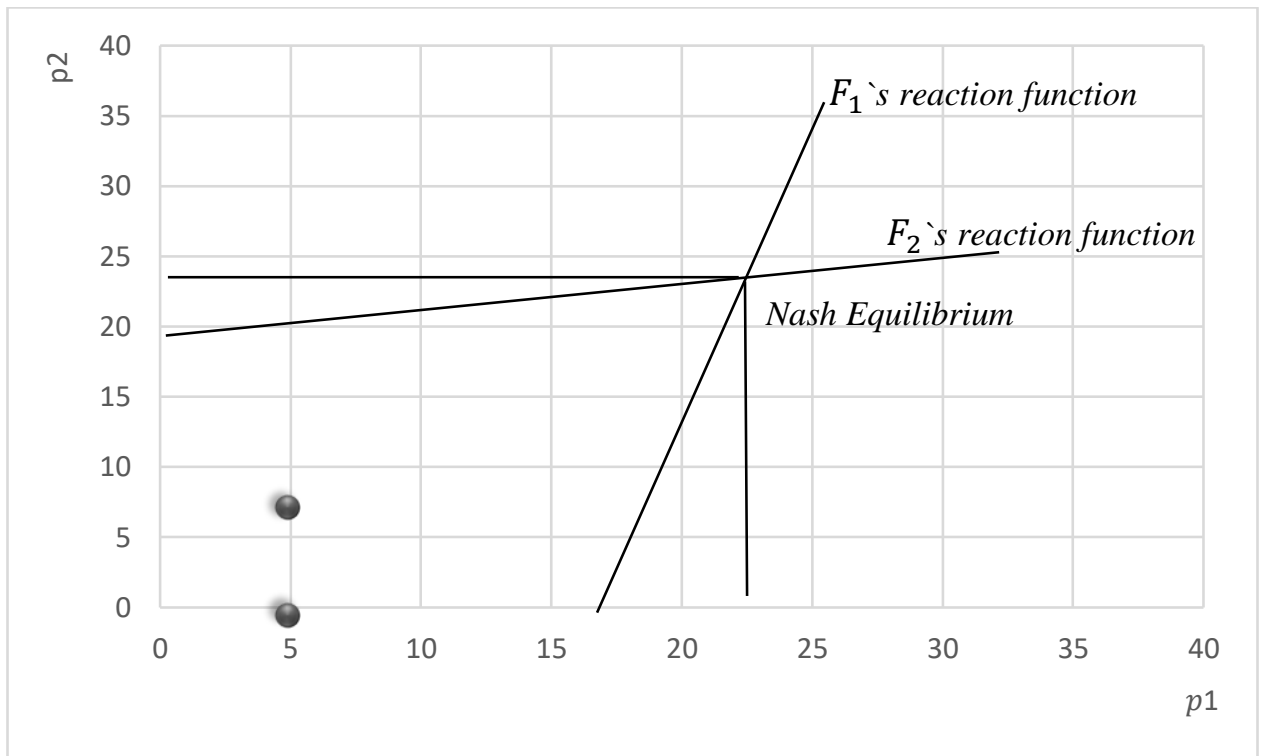

Figure 2. Nash equilibrium

Source: own processing.

Figure 2 shows the reaction functions separately for both players and the Bertrand-Nash equilibrium for this case. It is observed that the two players set their prices at close levels at this degree of differentiation. According to studies conducted for a discretized Bertrand-duopoly market with asymmetric constant marginal costs, the static Nash equilibrium highlights that the low-cost firm should set a price equal to the high-cost firm's marginal cost. Thus, the low-cost firm can gain the entire market. 
Now consider the case variation of the marginal cross-demand in the [0.1,2] interval, with an increment step of 0.1 . We see what happens when the marginal cross-demand becomes very small and approaches zero. The results are presented in Table 1.

By analyzing the results, we notice that $F_{1}$ does not have a well-behaved profit function, the opponent being more efficient. Even if the first player would want to deviate to any price close to his opponent, it fails to record higher or at least close gains. When the marginal cross-demand becomes very small and approaches zero, the second player gains at least twice as much as his opponent even if the set prices do not differ so significantly. For each marginal cross-demand between 1.2 and 2 the relative variation of the profit of company $F_{1}$ compared to the opponent is subunitary.

Table 1. Simulation of price, quantity and profit evolution

\begin{tabular}{|l|l|l|l|l|l|l|}
\hline \multicolumn{1}{|c|}{$z_{1}$} & $p_{1}^{*}$ & $p_{2}^{*}$ & $q_{1}^{*}$ & $q_{2}^{*}$ & $\pi_{1}^{*}$ & $\pi_{2}^{*}$ \\
\hline 0.1 & 17.28 & 22.24 & 54.06 & 64.89 & 274.10 & 928.98 \\
\hline 0.2 & 17.56 & 22.29 & 32.00 & 60.75 & 292.91 & 935.38 \\
\hline 0.3 & 17.84 & 22.34 & 33.11 & 60.96 & 312.44 & 941.83 \\
\hline 0.4 & 18.12 & 22.40 & 34.23 & 61.17 & 332.69 & 948.33 \\
\hline 0.5 & 18.40 & 22.45 & 35.35 & 61.38 & 353.68 & 954.88 \\
\hline 0.6 & 18.69 & 22.50 & 36.48 & 61.59 & 375.41 & 961.49 \\
\hline 0.7 & 18.97 & 22.56 & 37.61 & 61.80 & 397.91 & 968.15 \\
\hline 0.8 & 19.26 & 22.61 & 38.75 & 62.02 & 421.16 & 974.87 \\
\hline 0.9 & 19.55 & 22.67 & 39.90 & 62.23 & 445.20 & 981.64 \\
\hline 1 & 19.84 & 22.72 & 41.04 & 62.45 & 470.02 & 988.47 \\
\hline 1.1 & 20.13 & 22.77 & 42.20 & 62.66 & 495.64 & 995.36 \\
\hline 1.2 & 20.42 & 22.83 & 43.36 & 62.88 & 522.07 & 1002.30 \\
\hline 1.3 & 20.72 & 22.88 & 44.53 & 63.10 & 549.32 & 1009.30 \\
\hline 1.4 & 21.01 & 22.94 & 45.70 & 63.32 & 577.40 & 1016.36 \\
\hline 1.5 & 21.31 & 23.00 & 46.88 & 63.54 & 606.32 & 1023.48 \\
\hline 1.6 & 21.61 & 23.05 & 48.06 & 63.76 & 636.09 & 1030.66 \\
\hline 1.7 & 21.91 & 23.11 & 49.25 & 63.98 & 666.72 & 1037.90 \\
\hline 1.8 & 22.21 & 23.16 & 50.44 & 64.21 & 698.24 & 1045.20 \\
\hline 1.9 & 22.52 & 23.22 & 51.64 & 64.43 & 730.63 & 1052.56 \\
\hline 2 & 22.82 & 23.28 & 52.85 & 64.66 & 763.93 & 1059.98 \\
\hline
\end{tabular}

Source: Authors' own processing.

Thus, in this setting, the presence of any potential Bertrand-type competitor guarantees a competitive gain. Even if buyers tend to buy the product from the company that offers it at the lowest price, in reality there are buyers that purchase from the most expensive firms because of their intrinsic preference for the product sold by that company. In the case of the Bertrand model, the competition has a pro-competitive effect, the market equilibrium being efficient regardless of the limited number of competing companies. 


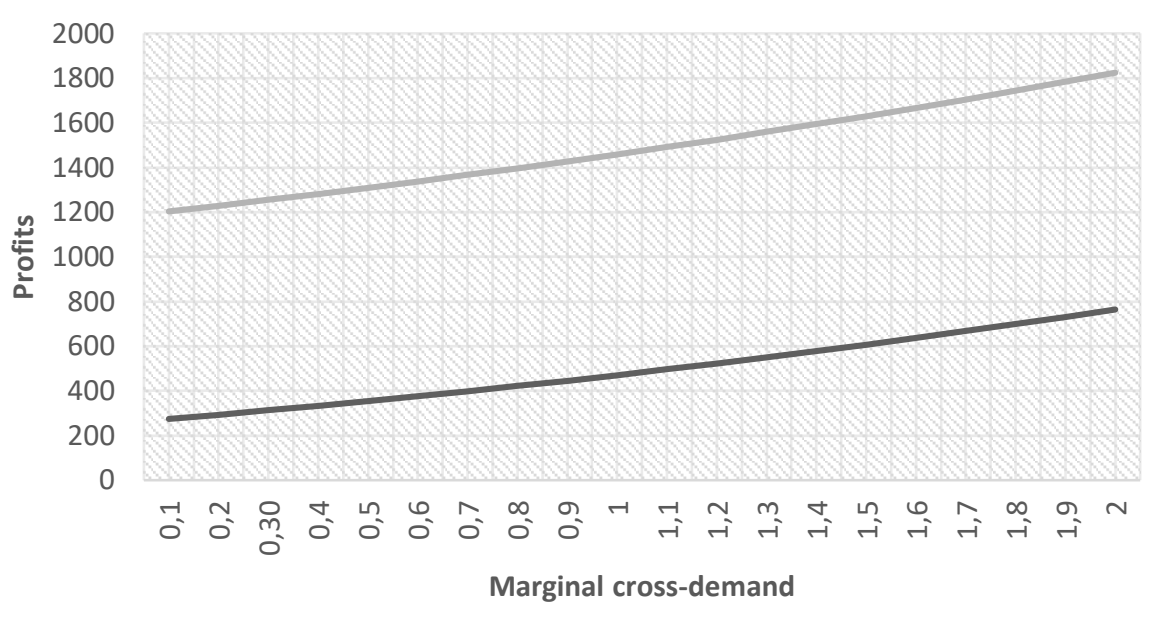

PICBE |

Figure 3. Profits depending on marginal cross-demand

Source: own processing.

\section{Conclusion}

Game theory provides a powerful tool for modeling the behavior of companies under asymmetric information, especially on the competitors' response to the decisions given by the price evolution. Since market conditions are external factors, and the competitive advantage is the internal external factor that determines the pricing, players aim to attract as large a segment of consumers and maximize profits. The exploration of competitive prices is done through the Bertrand model. Adaptive behavior in such a game is induced by the level of information asymmetry. If all firms in a market do not have access to perfect information, then the less than perfectly informed parties make suboptimal choices, which leads to an inefficient allocation of financial resources.

In the case of the Bertrand competition model the competitors decide on prices, looking to profit levels. If the demand functions are asymmetric for substituted products, the Bertrand-Nash equilibrium indicates large variations in competitors' profit levels. When the marginal crossdemand increases and is close to 2 (the maximum level possible in order to exist an equilibrium), then the difference of profit levels decrease and the efficiency of companies becomes comparable.

Numerous studies are needed for a broader analysis of price competition both static and dynamic. Future studies can be focused on Bayesian games, both with asymmetric demand and costs and also on repeated Bertrand competition, determining the gain of cooperation or the gain of deviation. Starting from the dynamic Bertrand model, we can analyze price competition through signaling games. The equilibrium adjustment in the case of the Bertrand duopoly can be done both in discrete time and in continuous time. Not least, the Bertrand model can be analyzed in incomplete information, considering the constant marginal cost of a continuous random variable.

\section{References}

Achstatter, G.A. (1996). Let game theory begin: Anticipating your rival, Investor's Business Daily, January 25, 1996.

Aoyagi, M. (2018). Bertrand competition under network externalities, Journal of Economic Theory, 178(C), 517-550.

Aumann, R. J. (1987). Correlated equilibrium as an expression of bayesian rationality, Journal of the Econometric Society, 55(1), 1-18. 
Bertrand, J. (1883). Review of Théorie Mathématique de la Richesse Sociale and Recherches sur les Principles Mathématique de la Théorie des Richesses, Journal des Savants, 499-508.

Blume, A. (2003). Bertrand without Fudge, Economics Letters, 78(2), 167-168.

Boone, J., Aylwin, M., Müller, W., \& Chaudhuri, A., (2012). Bertrand competition with asymmetric costs: Experimental evidence, Economics Letters, 117(1), 134-137.

Dastidar, K. (1995). On the existence of pure strategy Bertrand equilibrium, Economic Theory. 5(1), 19-32.

Day, G. S. (1990). Market Driven Strategy: Processes for Creating Value. The Free Press, New York.

Deneckere, R. J., \& Davidson, C. (1985). Incentives to form coalitions with Bertrand competition, The RAND Journal of Economics, 16, 473-486.

Dugar, S., \& Mitra, A. (2011). Bertrand competition with different marginal costs - the role of cost asymmetry, mimeo.

Glazer, R. (1991). Marketing in an information-intensive environment: Strategic implications of knowledge as an asset, The Journal of Marketing, 55(4), 1-19.

Hart, S. (2005). An interview with Robert Aumann, Macroeconomic Dynamics, 9, 683-740.

Higgins, R. S., Johnson, P. A., \& Sullivan, J. T. (2004). Spatial competition and merger, The B.E. Journals in Economic Analysis \& Policy-Topics, 4 (1), 1-37.

Hsu, J., \& Wang, X. H. (2005). On welfare under Cournot and Bertrand competition in differentiated oligopolies, Review of Industrial Organization, 27(2), 185-191.

Kaimann, D., \& Hoyer, B. (2019). Price competition and the Bertrand model: the paradox of the German mobile discount market, Applied Economics Letters, 26(1), 54-57.

Lofaro, A. (2002). On the Efficiency of Bertrand and Cournot Competition under Incomplete Information, European Journal of Political Economy, 18, 561-578.

Raju, J., \& Roy, A. (2000). Market Information and Firm Performance, Management Science, 46(8), 1075-1084.

Routledge, R. (2010). Bertrand competition with cost uncertainty, Economics Letters, 107(3), 356-359.

Rusescu, C., \& Roman, M.D. (2020). Product Differentiation Influence in the Cournot, Bertrand and Hierarchical Stackelberg Duopolies, Proceedings of BASIQ International Conference: New Trends in Sustainable Business and Consumption 2020, 298-305.

Sarvary, M., \& Parker, P. (1997). Marketing information: A competitive analysis, Marketing Science, 16(1), 24-38.

Singh, N., \& Vives, X. (1984). Price and quantity competition in a differentiated duopoly, The Rand Journal of Economics, 15(4), 546-554.

Spulber, D., F. (1995). Bertrand Competition when Rivals' Costs are Unknown, The Journal of Industrial Economics , 43(1), 1-11.

Suleymanova, I., \& Wey, C. (2011). Bertrand Competition in Markets with Network Effects and Switching Costs, DICE Discussion Paper No. 30.

Thomas, C. (2002). The effect of asymmetric entry costs on Bertrand competition, International Journal of Industrial Organization, 20(5), 589-609.

Tirole, J. (1988). The Theory of Industrial Organization. MIT Press. 